удК 577.153

T. KESVATERA

\title{
NOVEL APPROACH TO THE ELECTROSTATIC EFFECT IN ACETYLCHOLINESTERASE REACTIONS
}

T. KESVATERA. ATSETOOLKOLIINESTERAASI REAKTSIOONIDES ESINEVA ELEKTROSTAATILISE EFEKTI UUS KÄSITLUS

T. КЕСВАТЕРА. НОВЫИ ПОДХОД К ОБЪЯСНЕНИЮ ЭЛЕКТРОСТАТИЧЕСКОГО ЭФФЕКТА В РЕАКЦИЯХ АЦЕТИЛХОЛИНЭСТЕРАЗЫ

\section{(Presented by E. Lippmaa)}

Electrostatic interactions are among the key factors that determine the structure and function of proteins [ $\left.{ }^{1}\right]$. Of particular interest are contributions to the energetics of enzymatic reactions produced by strong electrostatic fields of protein molecules themselves and the role of counter-ions in protein environment.

In this communication electrostatic effects on ligand binding are exemplified on various cationic substrates and inhibitors of acetylcholinesterase (EC 3.1.1.7). Changes in the structure of the studied substrates and quasisubstrates, as characterized by the changes in the second-order rate constant $\left(k_{2} / K_{\mathrm{s}}\right)$ values of the enzyme acylation (i. e., in terms of structure-activity relationships), comprise nearly seven orders of magnitude. The changes in the structure include the variation of the distance between the reaction center and the onium atom in the leaving group of reagent molecules. Electrostatic effects on enzyme-ligand association were studied through the salt effect measurements, they were quantitatively described by the equation $[2,3]$

$$
p K_{s}=p K_{s}^{0}-\psi \log \left[M^{+}\right]
$$

where $\left[\mathrm{M}^{+}\right]$is the concentration of salt cation, $\psi$ is the parameter that characterizes the electrostatic interaction $\left[{ }^{2,4}\right]$ and $K_{s}{ }^{0}$ is the equilibrium constant at $\left[M^{+}\right]=1 M$.

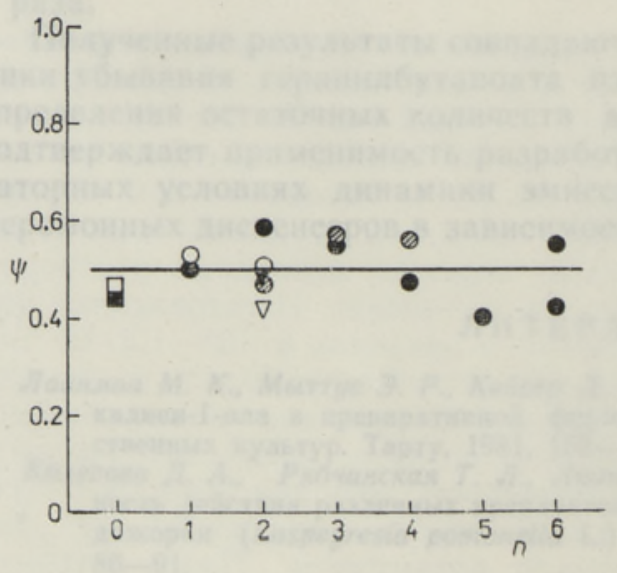

The plot of electrostatic effect parameter $\psi$ (Eq. 1) for the salt effect on acetylcholinesterase reactions with various substrates and inhibitors at $25^{\circ} \mathrm{C}$ and $\mathrm{pH} 7.5$ versus $n$, the number of methylene groups between the charged atom and the reaction center in the reagent molecule ( $n$ has been conventionaily set zero for alkylammonium inhibitors).

$\left.\mathrm{CH}_{3} \mathrm{C}(\mathrm{O}) \mathrm{O}\left(\mathrm{CH}_{2}\right)_{2} \mathrm{~N}+\left(\mathrm{CH}_{3}\right) \mathrm{C}_{4} \mathrm{H}_{4} \mathrm{O}{ }^{[2}{ }^{2}\right](\nabla)$, $\mathrm{CH}_{3} \mathrm{C}(\mathrm{O}) \mathrm{O}\left(\mathrm{CH}_{2}\right)_{\mathrm{n}} \mathrm{N}+\left(\mathrm{CH}_{3}\right)_{3}\left[{ }^{6}\right] \quad(\mathrm{O})$,

$\mathrm{CH}_{3} \mathrm{C}(\mathrm{O}) \mathrm{O}\left(\mathrm{CH}_{2}\right)_{n} \mathrm{~S}+\left(\mathrm{CH}_{3}\right) \mathrm{C}_{2} \mathrm{H}_{5}(\mathrm{O})^{*}$,

$\mathrm{CH}_{3} \mathrm{NHC}(\mathrm{O}) \mathrm{O}\left(\mathrm{CH}_{2}\right)_{2} \mathrm{~N}+\left(\mathrm{CH}_{3}\right)_{3}(\mathbf{\nabla})$,

$\left(\mathrm{C}_{2} \mathrm{H}_{5} \mathrm{O}\right)_{2} \mathrm{P}(\mathrm{O}) \mathrm{S}\left(\mathrm{CH}_{2}\right)_{\mathrm{n}} \mathrm{S}+\left(\mathrm{CH}_{3}\right) \mathrm{C}_{2} \mathrm{H}_{5}\left[{ }^{5}\right]$

(C), $\left(\mathrm{CH}_{3}\right)_{3} \mathrm{~N}+\mathrm{CH}_{2} \mathrm{CH}_{2} \mathrm{OH}(\square),\left(\mathrm{CH}_{3}\right)_{4} \mathrm{~N}^{+}$

(E).

* in fig. shaded circle. 
The main point of the present communication is illustrated in the Figure, which shows that electrostatic effects upon the enzyme-ligand association are similar despite the extremely large variations in the type and structure of ligands. The mean value of $\psi$ for the 15 compounds comprises 0.5 . The results indicate that the electrostatic effect does not depend upon the position of charge in the leaving part of acetic ester substrates, $\mathrm{CH}_{3} \mathrm{C}(\mathrm{O}) \mathrm{O}\left(\mathrm{CH}_{2}\right)_{n} \mathrm{~S}+\left(\mathrm{CH}_{3}\right) \mathrm{C}_{2} \mathrm{H}_{5}$, or organophosphorus quasisubstrates, $\left(\mathrm{C}_{2} \mathrm{H}_{5} \mathrm{O}\right)_{2} \mathrm{P}(\mathrm{O}) \mathrm{S}\left(\mathrm{CH}_{2}\right)_{n} \mathrm{~S}+\left(\mathrm{CH}_{3}\right) \mathrm{C}_{2} \mathrm{H}_{5}$ [5] $^{5}$ The electrostatic contribution to the binding of these two types of acetylcholinesterase reagents is similar despite the fact that leaving parts of acetic ester substrates and organcphosphates were shown to bind in different areas of the active center of the enzyme [ $\left.{ }^{7}\right]$.

These results clearly contradict the classical view about the role of a structurally fixed anionic site which is assumed to make a specific electrostatic contribution to the binding of cationic substrates in the active site of acetylcholinesterase. Instead, the importance of charged groups on the enzyme molecule has to be stressed. Although the electrostatic interactions for proteins as polyampholytes are difficult to model, it is reasonable to assume the high localization of ccunterions in the vicinity of proteins, analogously to the counterion condensation hypothesis for linear polyelectrolytes with homogeneous charge distribution $\left.{ }^{4}\right]$. This assumption is in agreement with the principle of electroneutrality and seems to be supported, e. g., by the recent measurements of coupled transport of sodium chloride during diffusion of bovine serum albumin $\left[^{8}\right]$.

As a matter of fact, Eq. 1 based on the counterion condensation theory developed by Manning [ ${ }^{3,4}$ ] has been shown to provide an excellent description for the effect of salt concentration upon the acetylcholinesterasecationic ligand association $[2,5,6]$. Accordingly, the electrostatic contribution can be entirely explained as resulting from the counterion displacemont on the ligand binding. Once the displacement of counterions takes place, there is no reason to assume that any additional mechanism is requircd to compensate the possible «antihydrophobicity effect» due to the presence of charged atom in the ligand molecule $\left[{ }^{9}\right]$. Moreover, in agreement with the results of quantitative structure-activity relationship study of acetylcholinesterase-catalyzed hydrolysis of cationic substrates $\left.{ }^{9}\right]$ there is no contribution to the energetics of the reaction left that would require the «anionic site» in the active center of the enzyme.

\section{Conclusion}

Electrostatic effect on acetylcholinesterase-cationic ligand association, being independent of the monovalent ligand structure, is entirely determined by the electrostatic field of ionic charges on the enzyme molecule. Thus, the anionic site is not required to account for the outstanding specificity of acetylcholinesterase in hydrolysis of cationic substrates, e. g., acetylcholine.

\section{R EFERENCES}

1. Gilson, M. K., Honig, B. H. Energetics of charge-charge interactions in proteins // Proteins, 1988, 3, 32-52.

2. Tõugu, V., Pedak, A., Kesvatera, T., Aaviksaar, A. Acetylcholinesterase as polyelectrolyte in reaction with cationic substrates // FEBS Lett., 1987, 225, N 1, 2, 77-81.

3. Record, M. T. jr., Lohman, T. M., De Haseth, P. Ion effects oil ligand-nucleic acid interactions // J. Mol. Biol., 1976, 107, N 2, 145-158. 
4. Manning, G. S. Limiting laws and counterion condensation in polyelectrolyte solutions. I. Colligative properties. // J. Chem. Phys., 1969, 51, N 3, 924-938.

5. Kesvatera, T., Järv, J. Salt effects in acetylcholinesterase reactions with O,O-diethylthiophosphates // Bioorg. Chem., in press.

6. Kesvatera, T., Langel, A., Järv, J. Salt effects on cholinesterase-catalyzed hydrolysis of acetylcholine // in preparation.

7. Järv, J. Stereochemical aspects of cholinesterase catalysis // Bioorg. Chem., 1984, 12, N 2, 259-278.

8. Leaist, $D . G$. Coupled transport of sodium cliloride driven by diffusion of bovine serum albumin // J. Phys. Chem., 1986, 90, N 25, 6600-6602.

9. Järv, J., Kesvatera, T., Aaviksaar, A. Charge effect in the acetylcholinesterase hydrolysis of acetic esters // Org. React., 1976, 13, N 4, 501-505.

Academy of Sciences of the Estonian SSR,

Institute of Chemical Physics and Biophysics

Received

Apr. 10, 1989 


\section{EESTI NSV TEADUSTE AKADEEMIA ULDKOGU KOOSOLEK}

\section{4. jaanuaril 1989}

4. jaanuaril 1989 Tallinnas toimunud Eesti NSV Teaduste Akadeemia üldkogu koosoleku päevakorras oli akadeemia uue pōhikirja arutamine ja uurimisasutuste direktorite ametisse kinnitamine.

Koosoleku avas Eesti NSV Teaduste Akadeemia president Karl Rebane, kes ühtlasi informeeris eelmise üldkogu otsuste täitmisest.

Ettekande akadeemia pōhikirja muutmisest ja parandustest tegi akadeemik Erast P a rmas to. Kaasettekandega esines akadeemik Jaan Ei n a s to. Läbirääkimistel vōtsid sōna akadeemikud Karl Rebane, Endel Li p pmaa, Jaan Re bane, Arno Köörna, Ilmar Öpik ja Harald Keres ning korrespondentliige Tšeslav L ušt šik.

Oldkogu kinnitas ENSV TA uurimisasutuste direktoriteks järgmised teadlased: Füüsika Instituudi direktoriks füüsika-matemaatikadoktor Arvi F r e i be r g, Küberneetika Instituudi direktoriks korrespondentliige Ulo J a a ks o o, Geoloogia Instituudi direktoriks uueks perioodiks korrespondentliige Dimitri $\mathrm{Kaljo}$, Eksperimentaalbioloogia Instituudi direktoriks uueks perioodiks bioloogiadoktor Oskar Priilinn, Tallinna Botaanikaaia direktoriks geograafiakandidaat Andres Tarand, Majanduse Instituudi direktoriks majanduskandidaat Olev Lu g us ning Keele ja Kirjanduse Instituudi direktoriks filoloogiakandidaat Tõnu
Seilenthal. Ohtlasi avaldati tänu kauaaegse tulemusrikka tegevuse eest uurimisasutuse direktorina akadeemik H. Abenile, korrespondentliikmele P. S a a rile, majandusdoktor R. Ots a sonile, bioloogiadoktor J. Martinile ja filoloogiakandidaat $M$. R e m m e lile.

Koosolekul andis president Karl Rebane akadeemik Hillar A benile ja Küberneetika Arvutustehnika Erikonstrueerimisbüroo direktorile Kalju Lepikule üle NSV Liidu Teaduste Akadeemia aukirjad kollektiivi «Start» töö eduka lōpetamise puhul. Mikk T it ma t onnitleti EKP Keskkomitee sekretäriks valimise puhul.

Oldkogu tegi NSV Liidu Teaduste Akadeemia Presiidiumile ettepaneku esitada NSV Liidu rahvasaadiku kandidaadiks Eesti NSV Teaduste Akadeemia president Karl Rebane. Tallinna Keskvalimisringkonnas nr. 456 seati NSV Liidu rahvasaadiku kandidaadiks Keemilise ja Bioloogilise Füüsika Instituudi direktor Endel Li p p m a a.

Koosolekust vōttis osa 17 akadeemikut 26-st ja 18 korrespondentliiget 26-st. Külaliste hulgas olid EKP Keskkomitee sekretär Mikk T itma ja EKP Keskkomitee sektorijuhataja Tiit Koldits.

Koosolekul vastuvõetud otsused on avaldatud «Toimetiste» ühiskonnateaduste, bioloogia- ja füüsika-matemaatikaseeria 1989. aasta 3 . numbrites.

\section{Ōiendus}

30. märtsil 1988 toimunud Eesti NSV Teaduste Akadeemia 42. aastakoosolekul anti Paul Kogermani mälestusmedal Põlevkivi Teadusliku Uurimise Instituudi teadusdirektorile Viktor Jefimovile. 
O потерях $\mathrm{HNO}_{3}$ с газами при азотнокислотном разложении фосфоритов Прибалтики. Аасамяэ Э., Саар В. // Изв. АН Эстонин. Химия, 1989, т. 38, № 3, с. 145-149 (рус.; рез. эст., англ.)

Исследована зависимость потерь $\mathrm{HNO}_{3}$ от типа фосфорита и от технологическнх параметров процесса - температуры, количества и концентрации $\mathrm{HNO}_{3}$, продолжнтельности разложения. Установлено, что потери $\mathrm{HNO}_{3}$ самые низкие при разложении феррондных и магнезиальных фосфоритов (например, Кингисеппского месторождения), а характер зависимости потерь от технологического режима процесса одинаков у разных типов фосфорита. Рис. 1. Табл. 2. Библ. 17 назв.

\section{удК 553.635}

О термодинамической вероятности получения сульфида кальция из фосфогипса. Триккель А., Тюрн Л., Куусик Р. // Изв. АН Эстонни. Химия, 1989, т. 38, № 3, с. 150158 (рус.; рез. эст., англ.)

В целях определения вероятности получения из фосфогипса сульфида кальция проведен термодинамический анализ систем $\mathrm{CaSO}_{4}-\mathrm{H}_{2}-\mathrm{H}_{2} \mathrm{O}, \mathrm{CaSO}_{4}-\mathrm{CO}-\mathrm{CO}_{2}$ и $\mathrm{CaSO}_{4}-\mathrm{C}-\mathrm{O}_{2}$ в температурном интервале $800-1400 \mathrm{~K}$ на базе 22 реакций. Вероятность протекания реакций оценивали по изменению энергии Гиббса с учетом парциальных давлений газовых компонентов, по равновесным парциальным давлениям продуктов реакций, а также с построением диаграмм состояния на оснозе констант равновесия. Установлено, что для направления продесса в сторону образования $\mathrm{CaS}$ необходима сравнительно низкая температура - ниже $1200 \mathrm{~K}$, высокий восстановнтельный потенциал газовых реагентов, шихтовка $\mathrm{K} \mathrm{CaSO}_{4}$ твердого восстановителя и применение возможно чнстого фосфогипса с минимальным содержанием полуторных оксидов и кварца. Рис. 5. Библ. 10 назв.

удК $543.544 .45: 547.313$

Межлабораторная воспроизводимость характеристик удерживания $H$-алкенов и н-алкинов на капиллярных колонках. Кунингас К., Ранг С., Кайлас Т., Король А., Дубовик М. // Изв. АН Эстонии. Химия, 1989, т. 38, № 3, с. $159-166$ (рус.; рез. эст., англ.)

Определена межлабораторная воспроизводимость характеристнк удерживания (времсна и индексы удерживания) н-алкенов и н-алкннов на капиллярных колонках с неполярными и полярными жндкими фазємн. Установлено, что идентифнкация изомеров (с точностью \pm 1 ед. ин.) на сквалане и на OV-101 возможна по литературным данным, а в случае OV-17 и OV-225 следует экспернментально определить расхождения по некоторым доступным эталонам и учитывать их при использовании литературных данных. Табл. 5. Бнбл. 21 назв.

удК $543.54: 547.322$

Капиллярная газовая хроматография метилзамещенных 6-хлор-6-метил-2(E)-гептенов. Эрм А., Мукс Э., Лыйвеке И., Хейзяли М. // Изв. АН Эстонии. Химия, 1989, т. 38, № 3, с. $167-173$ (рус.; рез. эст., англ.)

Кізучены газохроматографические характеристики (индексы удерживания $I$, их температурные и структурные инкременты) 18 метилзамешенных 6-хлор-6-метнл-2(E)-гептенов на неполярной силиконовой фазе OV-101 и на высокополярной фазе - 1,2,3-трис(2-цианэтокси)пропане, нанесенных на стеклянные капиллярные колонки. Установлено, что величина вклада метильной группы в индекс удерживания I зависит от ее положения в молекуле. Табл. 2. Библ. 14 назв.

\section{удК 543.544}

Использование фенилаланина и тирозина как элюента в ионной хроматографии. Сорбция компонентов элюента в подавляющей колонке. Нваск Ю., Пенчук Я. // Изв. АН Эстонин. Химия, 1989, т. 38, № 3, с. $174-177$ (англ.; рез. эст., рус.)

Изучена сорбция аминокислотного элюента в подавляющей колонке. Разработаны условия для ионохроматографического определения компонентов элюента, а также условия, при которых всдется детектирование анионов в двухколоночной ионной хроматографии с использованием аминокислотного элюента. Рис. 3. Бнбл. 5 назв. 
Применение дырочной групповой модели к системам с ненасыщенными углеводородами. Викторов А., Кудрявцева Л., Куус М. // Изв. АН Эстонии. Химия, 1989, т. 38, № 3, c. $178-184$ (рус.; рез. эст., англ.)

Для расчета парожидкостного равновесия (ПЖР) и энтальпий смешения (HE) в системах, образованных 1-алкенами и 1-алкинами с н-алканами, применена квазихимическая групповая модель с вакансиями. Определены энергетические параметры модели для групп $\mathrm{CH}_{2}=\mathrm{CH}$ и $\mathrm{HC} \equiv$. C применением параметров, определенных только по данным о свойствах чистых жидкостей, получено удовлетворительное согласие с экспериментом результатов расчета ПЖР в системах 1-алкен н-алкан и совместного предсказания ПЖР и $H^{E}$ в системах 1-алкин-H-алкан. Рис. 3. Табл. 2. Библ. 16 назв

\section{УДК 541.123}

Равновесие жидкость-пар в бинарных системах 1-этилциклопентен-н-гептан, -толуол, -диметилсульфоксид. К Кирсс Х., Винк И. // Изв. АН Эстонии. Химия, 1989, т. 38, № 3, с. $185-189$ (рус.; рез. эст., англ.)

Эбуллиометрически определена концентрационная зависимость температур кипения смесей 1-этилциклопентена с н-гситаном и толуолом при давлениях 200, 400, 600 и 760 мм рт. ст., а с диметилсульфоксидом при 100, 150 и 200 мм рт. ст. Равновесие жидкость-пар во всех исследованных системах описано уравнением Редлиха-Кистера, в углеводородных системах также уравнением Вильсона. Установлено, что все исследованные бинарные системы характеризуются положительным отклонением от законов идеальных растворов. В условиях опыта жидкая фаза в системе 1-этилциклопентен-диметилсульфокснд расслаивается. Изучено влияние давления на параметры гетероазеотропа 1-этилциклопентен-диметилсульфоксид. Рис. 1. Табл. 5. Библ. 7 назв.

\section{УДК $542.942 .7: 547.565: 542.951 .8$}

Осаждение динитрозометилрезорцина алкиламинами. Ноханнес И., Мельдер Л. // Изв. АН Эстонин. Химия, 1989, т. 38, № 3, с. 190-196 (рус.; рез. эст., англ.)

Установлено, что в нейтральных и слабокислых растворах 2,4-динитрозо-5-метилрезорцин и алкиламины $\mathrm{C}_{10}-\mathrm{C}_{16}$ образуют осадок с молярным соотношением компонентов 1:1. Найдена функциональная зависимость произведения растворимости образующегося соединения от длины алкильного радикала амина. Получено уравнение, описывающее зависимость степени осаждения динитрозометилрезорцина от $\mathrm{pH}$, исходных концентраций реагентов и произведения растворимостн. Показано, что рассчитанные по этому уравнению данные хорошо согласуются с экспериментальнымн. Рис. 2. Табл. 2. Библ. 5 назв.

\section{УДК 547.298 .1 .07}

Изготовление анионных поверхностно-активных веществ на основе жировых отходов рыбоконсервной промышленности. Иьерс Я., Урбель Х. // Изв. АН Эстонни. Химия, 1989 , т. 38, № 3, с. $197-201$ (рус.; рез. эст., англ.)

В настсящее время в косметике предпочитают использовать поверхностно-активные вещества (ПАВ) натурального пронсхождения, которые обладают хорошей моющей способностью, оказывают мягкое дерматологическое дейстние и легко подвергаются биоразложению. Нами в качестве сырья использованы не традиционные пищевые масла и нефтепродукты, а жировые отходы, постоянно образующиеся на всех рыСоперерабатывающих предприятиях. В работе описана технология утилизации жировых отходов рыбсконсервной промышленности и получение косметических ПАВ и шампуня на их основе. Технология синтеза нового анионного ПАВ - двойной соли триэтаноламина и натрия ациламидоэтнлсульфоянтарной кислоты - является экологически безвредной, ресурсосберегающей и практически безотходной. Библ. 4 назв. 
Испытание сходимости итераций программы DHLET, основанной на минимизирующей подпрограмме LETAG. Мелоун М., Эббер А. // Изв. АН Эстонин. Химия, 1989, т. 38, № 3, с. 202-208 (рус.; рез. эст., англ.)

Программа DHLET рассчитывает три неизвестных параметра (один из которых является термодинамической константой диссоциации) в математической модели, описывающей зависимость смешанной константы диссоциации от ионной силы. Программа работает итерациями и в каждой итерации, выполняемой подпрограммой LETAG, происходит аппроксимация минимизируемой функции (остаточной суммы квадратов) поверхностью второго порядка (квадрикой) и находятся улучшенные значения искомых параметров. Исходя из сгенерированных экспериментальных данных исследована сходимость работы программы при различных начальных значениях искомых параметров, различных шагах варьирования параметров и стратегии изменения шагов варьирования при переходс к последующей итерации. Рассмотрены эвристический и алгоритмический режимы работы программы. Показано, что подпрограмма LETAG, которая не требует знания частных пронзводных, успешно применима для нахождения нензвестных параметров в математических моделях сложной формы. Программа DHLET написана на Фортране IV. Рис. 2. Табл. 3. Бнбл. 4 назв.

\section{удК 547.582 .2}

Синтез и характеристика бензилмефената и бензилортофената. [Кр. сообщ.]. Кыбу M., Сиймер Э. // Изв. АН Эстонии. Химия, 1989, т. 38, № 3, с. 209-212 (на рус. яз.)

Осуществлен синтез бензилмефената и бензилортофената из натриевой соли соответствующей кислоты и бензнла хлористого в среде этилового спирта. Приведены некоторые физико-химические показатели продуктов, а также данные УФ- и ИК-спектров. Рис. 1. Табл. 1. Библ. 7 назв.

\section{удК $621.039 .85: 632.936 .2$}

Определение динамики эмиссии феромонов из препаративных форм методом радиомеченых компонентов. [Кр. сообщ.]. Сийрде К., Сапегин В., Кудрявщев И., Лээтс К. // Изв. АН Эстонин. Химия, 1989, т. 38, № 3, с. 213-215 (на рус. яз.)

Предложена методика, позволяющая непосредственно измерять скорость испарения компонентов феромонов из диспенсеров в течение всего цикла их работы при помощи радиомеченых компонентов феромонов и определять прн этом влияние температуры воздуха на динамику эмиссин. Проанллзирована динамика эмиссии геранилбутаноата из препаративных форм на основе резины. Рис. 1. Библ. 9 назв.

\section{удК 577.153}

Новый подход к объяснению электростатического эффекта в реакциях ацетилхолинэстеразы. [Кр. сообщ.]. Кесватера Т. // Изв. АН Эстонии. Химия, 1989, т. 38, № 3, с. 216218 (на англ. яз.)

Показано, что электростатический вклад в связывание различных катионных субстратов и ингибиторов на активной поверхности ацетилхолинэстеразы полностыю определястся электростатическим полем, создаваемым нонными группами, расположенными на молекуле фермента. Исходя из этого отпадает необходимость предположения о наличии специфического анионного центра на каталитической поверхности ацетилхолинэстеразы. Рис. 1. Библ. 9 назв. 


\section{SISUKORD}

E. A a s a mä e, Veera Saar. $\mathrm{HNO}_{3}$ kaod gaasidega Baltikumi fosforiitide lämmastikhappelisel lagundamisel. Resümee

A. Trikkel, L. Türn, R. Kuusik. Fosfokipsist kaltsiumsulfiidi saamise termodünaamilisest tōenäosusest. Resümee

Kai Kuningas, Silvia Rang, Tiiu Kailas, A. Korol, Margarita Dubovik. Kapillaarkolonnide abil määratud $n$-alkeenide ja $n$-alküünide retentsiooniparameetrite laboritevaheline reprodutseeritavus. Resümee

A. Erm, Elvi Muks, Ilme Lõiveke, Mare Heinväli. 6-kloor-6-metüüi-2(E)-hepteeni metüülderivaatide kapillaargaasikromatograafia. Resümee

J. Ivask, J. Pentšuk. Fenüülalaniini ja türosiini kasutamine eluendina ioonkromatograafias. Eluendi koostisosade sorbeerumine supressorkolonnis. Resümee

A. Viktorov, L. Kudrjavtseva, M. Kuus. Vakantsidega kvaasikeemilise grupimudeli rakendamine küllastumatuid süsivesinikke sisaldavatele süsteemidele. Resümee

Helle Kirss, I. Vink. Vedeliku ja auru tasakaal binaarsetes süsteemides 1-etüültsüklopenteen- $n$-heptaan, - tolueen, -dimetüülsulioksiid. Resümee .

Ille Johannes, L. Mölder. Dinitrosometüülresortsiini sadestamine alküülamiinidega. Resümee

J. Jõers, Helje Urbel. Ánioonsete pindaktiivsete ainete saamine kalatööstuse heitrasvadest. Resümee

M. Meloun, A. Ebber. Minimeerival alamprogrammil LETAG baseeruva mittelineaarse vähimruutude ülesande koonduvuse uurimine dissotsiatsioonikonstantide arvutamise programmi DHLET põhjal. Resümee

\section{LOHITEATEID}

Malle Kõbu, E. Siimer. Bensüülmefenaadi ja bensüülortofenaadi süntees ja iseloomustus (vene keeles)

K. Siirde, V. Sapegin, I. Kudrjavtsev, K. Lääts. Feromoonide emissiooni dünaamika määramine preparatiivsetest vormidest radiomärgitud komponentide meetodil (vene keeles)

T. Kesvatera. Atsetüülkoliinesteraasi reaktsioonides esineva elektrostaatilise efekti uus käsitlus (inglise keeles)

\section{EESTI TEADUSTE AKADEEMIAS}

Eesti NSV Teaduste Akadeemia üldkogu koosolek 4. jaanuaril 1989

\section{СОДЕРЖАНИЕ}

7. Аасамяэ, Вера Саар. О потерях $\mathrm{HNO}_{3}$ с газами при азотнокислотном разложении фосфоритов Прибалтики

А. Триккель, Л. Тюрн, Р. Куусик. О термодинамической вероятности получения сульфида кальция из фосфогипса

Кай Кунингас, Сильвия Ранг, Тийу Кайлас, А. Король, маргарита Дуубовик. Межлабораторная воспроизводимость характеристик удерживания $\boldsymbol{H}$-алкенов и н-алкинов на капиллярных колонках .

А. Эрм, Эльви Мукс, Нльме Лыйвеке, Маре Хейнвяли. Капиллярная газовая хроматография метилзамещенных 6-хлор-6-метил-2 $(E)$-гептенов .

Ю. Иваск, Я. Пенчук. Использование феннлаланина и тирознна как элюента в ионной хроматографин. Сорбция компонентов элюента в подавляющей колонке. Резюме

А. Викторов, Л. Кудряөцева, М. Куус. Применение дырочной групповой модели к системам с ненасыщенными углеводородами .

Хелле Кирсс, И. Винк. Равновесие жидкость-пар в бинарных системах 1-этилциклопентен-н-гептан, -толуол, -диметилсульфоксид

Илле Ноханнес, Л. Мельдер. Осаждение динитрозометилрезорцина алкиламинами

С. Ныерс, Хелье Урбель. Изготовление анионных поверхностно-активных веществ на основе жировых отходов рыбоконсервной промышленности

M. Мелоун, А. Эббер. Испытание сходимости итераций программы DHLET, основанной на минимизирующей подпрограмме LETAG .

\section{КРАТКИЕ СООБЩЕНИЯ}

Малле Кыбу, Э. Сиймрд. Синтез и характеристика бензилмефената и бензилгртофената (на рус. яз.)

К. Сийрде, В. Сапегин, И. Кудрявщев, К. Лээтс. Определение динамики эмиссии феромонов из препаративных форм методом радиомеченых компонентов (на рус. яз.)

T. Кесватера. Новый подход к объяснению электростатического эфффекта в реакциях ацетилхолинэстеразы (на англ. яз.) 


\section{CONTENTS}

E. Aasamäe, Veera Saar. Losses of $\mathrm{HNO}_{3}$ with gases in acidulating Baltic phosphorites by nitric acid. Summary

A. Trikkel, L. Türn, R. Kuusik. Thermodynanical probability of getting calcium sulphide from phosphogypsum. Summary .

Kai Kuningas, Silvia Rang, Tiiu Kailas, A. Korol, Margarita Dubovik. Interlaboratory reproducibility of the retention characteristics of $n$-alkenes and $n$-alkynes on capillary columns. Summary

A. Erm, Elvi Muks, Ilme Lõiveke, Mare Heinväli. Capillary gas chromatography of methyl substituted 6-chlor-6-methyl-2(E)-heptenes. Summary .

J. Ivask, J. Pentchuk. Application of phenylalanine and tyrosine as eluents in ion chromatography. The sorption of the eluent ingredients in the suppressor column

A. Victorov, L. Kudryavtseva, M. Kuus. Application of hole group-contribution model to the systems with unsaturated hydrocarbons. Summary

Helle Kirss, J. Vink. Vapor-liquid equilibrium in the binary systems of 1-ethylcyclopentene with $n$-heptane, toluene and dimethylsulphoxide. Summary

Ille Johannes, L. Mölder. Precipitation of dinitrosomethylresorcinol by alkylamines. Summary

J. Jõers, Helje Urbel. The process of preparing anionic surfactants on the basis of fatty wastes of the fish-processing industry. Summary

M. Meloun, A. Ebber. Proof of the iteration convergence of the DHLET programme based on the minimization subroutine LETAG. Summary

\section{SHORT COMMUNICATIONS}

Ma!le Kõbu, E. Siimer. Synthesis and characteristics of benzylmephenate and benzylorthophenate (in Russian)

K. Sïrde, V. Sapegin, I. Kudryavtsev, K. Lääts. Estimation of the dynamics of pheromone emission from dispensers by the radiolabeled components method (in Russian) . . . . . . . . . . . . . .

T. Kesvatera. Novel approach to the electrostatic eifect in acetylcholinesterase reactions

Toimetuselt. 16. juunil 1989 Eesti NSV Ministrite Nõukogu määrusega kinnitatud nimetus Eesti Teaduste Akadeemia kajastub samast ajast ka meie ajakirja nimes ( «Eesti Teaduste Akadeemia Toimetised»), kuid trükitehnilistel pôhjustel jääb varasem nimekuju ajakirja kaanele 1989. aasta iôpuni. Toimetus palub viitamisel kasutada uut nime.

От редакции. Решение Совета Министров Эстонской ССР от 16 июня 1989 г., утвердившее название Академни наук Эстонии, имеет прямое отношение и к названию нашего журнала (Известия Академии наук Эстонии), но по технико-производственным причннам прежнее название журнала останется на обложке до конца 1989 г. Редакция просит учесть это и при ссылках использовать новое название.

Editor's note. Since June 16, 1989 our journal is called The Proceedings of the Estonian Academy of Sciences but for technical reasons the former name is printed on the cover till the end of 1989. We ask you to take this into consideration when referring to our publication. 

80 коп.

Индекс 78155 